\section{Nietzsche, valores humanos e devir da técnica}

\section{RESUMO}

A partir do legado de Friedrich Nietzsche, o presente trabalho propõe um diálogo com o seu pensamento sobre a técnica e 0 devir do homem.

\section{ABSTRACT \\ In this article the author reflects upon some thoughts of Friedrich Nietzsche about technics and the becoming of man. \\ PALAVRAS-CHAVE (KEY WORDS) \\ - Técnica (Technics) \\ - Devir (Becoming) \\ - Nietzsche}

Francisco E. Menezes Martins Prof. Dr. do PPGCOM - FAMECOS/PUCRS
O títULO do PRESENTE TEXTO refere-se a um pensar com Nietzsche o homem em sua potência de vida, ante a técnica e no devir do mundo. A lógica da técnica possui as palavras para o consenso interpretativo de uma moral da positividade e já não há mais tempo que não se deixe levar pelos discursos a seu respeito.

No excesso das interpretações, nenhuma generosidade, apenas apropriações de fragmentos de vidas cristalizadas em textos. Legado para um devir que dissimula as causas e vê triunfar no efeito a civilização. Autores, idéias, textos: transmissão em rede das vontades de visualização e de ser visualizado.

Desde uma perspectiva frente ao tempo, a partir de leituras da obra de Friedrich Nietzsche(1844-1900), o pensamento afirmativo da vida pode vir a ser fiel com a intenção interpretativa do pesquisador.

Um pensamento que não se deixa levar pelos triunfos da positividade de seu tempo. Um mundo de multiplicidades que inspira palavras e imagens. Tudo o que pode circular nas redes tende a ter uma dilatação potencializada em diferentes graus, dependendo dos pontos onde chega ou se é ambiente receptivo para os mesmos. Culturas que trocam (ciber)espaço e tempo.

Desde que a palavra servia para expressar o pensamento do a-se-pensar, em Heráclito, nos tempos da origem do pensamento ocidental, até a atualidade, é possível relatar a história de um desvio, uma redução da potência humana, que é, por outra parte, o aumento da crença da metafísica com Platão e Aristóteles.

Quando determinado pensamento vence, seus rivais tornam-se obscuros. Com isso, até mesmo tem confundida sua profundidade com a dificultade de se fazer 
entender ou de ter menos 'razão'. Se os 131 fragmentos de Heráclito não são a totalidade de sua obra e sofreram a edição interessadamente romana, de Cícero e, já na modernidade, a ação da metafísica especulativa de Hegel e da filologia de Nietzsche. Em todos os casos, há a dificuldade de análise dos fragmentos.

Da mesma forma, Nietzsche sofreu os abusos da interpretação de suas obras pela irmã, desde as edições interesseiras, até a criação frankensteiniana de a Vontade de Potência, a partir de notas dispersas: um livro que nunca existiu, mas cuja intenção a aproxima moralmente de Cícero. Além disso, as mais distintas correntes filosóficas, políticas e religiosas descobriram o prazer da violação intelectual póstuma. Já eram tempos de aceleração e, alguns anos após seu afastamento da linguagem e dos relacionamentos humanos, em 1889, surgiram os mal-entendidos.

Quando o discurso de um filósofo se expande após sua morte, sempre haverá violações de seu pensamento. No caso de Nietzsche, o século XX foi testemunha de como o enigma de sua existência despertou visões e versões sobre o que o filósofoandarilho realmente quis dizer. ${ }^{1}$

Neste ponto, o problema da liberação da metafísica em seu pensamento é polêmica, sendo Heidegger um pensador que o enquadra como o último metafísico. Aqui, considera-se que Nietzsche era um pensador da interioridade e não da transcendência. De qualquer forma, $O$ filósofo solitário ou o ausente proporcionam a aproximação dos rivais de Ulisses. Mas uma interpretação consonante com o sentido nietzschiano pode dissipar os demais pretendentes de Penélope com a volta do pensamento como força, que busca o mundo no próprio mundo. Uma realidade da vida e não a vida da realidade da razão. ${ }^{2}$

A moral $^{3}$ é um fluxo que religa o homem a seu ambiente. Das diversas intenções fundadoras de tal "domesticação ou 'melhoramento' do rebanho", a utilitarista faz surgir o bom da moral do escravo, ${ }^{4}$ aquela em que o nobre-malvado é a negação que permite o surgimento do novo conceito de bom. Distante da elaboração das próprias regras, o sentimento gregário fortalece a fraqueza e prega o enfraquecimento do forte, em nome de invertidas visões de mundo. Punir o triunfo e a força com o sentimento de culpa. ${ }^{5}$ Exaltar a humildade como valor em si e não como a transfiguração da covardia e do medo. Eram outros tempos. As neblinas da metafísica, da religião e da moral paralisavam a criação de mundos a partir do jogo heraclitano do eterno criar-destruirrecriar. ${ }^{6}$

O mundo suspenso pela elevação do transcendente. $O$ jogo perde para a regra. Antes, a regra até poderia servir para dar ânimo ao jogo. Agora, o jogo não serve para a regra. Como tal, a regra teve que inventar um "jogo ideal" para que "os jogadores" não perdessem a disposição e, principalmente, para que atrás de sua máscara surgisse o "mundo verdadeiro".

Assim, a moral (utilidade, poder e controle social e humano) habita o ser e os entes. A pálida interpretação é reforçada pela equaçãosocrática: "razão = virtude = felicidade" e pela elevação do bem a partir da idéia do sábio.

Antes de se questionar sobre qual finalidade possui um homem, uma civilização, um mundo, é pertinente perguntar sobre que fundamentos o pensamento ocidental se instaurou e que lugar ocupa a técnica moderna como algo a-se-pensar. ${ }^{8}$

Em outros tempos, o passado trazia o peso da consciência histórica e os valores orientavam as palavras: "Desta mesma forma, Nietzsche apodera-se das interpretações que são já prisioneiras umas das outras. Não há para Nietzsche um significado original. As mesmas palavras não são senão interpretações, ao longo da sua história, antes de se converterem em símbolos, interpretam e têm significado, finalmente, porque são interpretações 
essenciais". 9

Atualmente não faltam palavras nem coisas. O espírito de igualdade se expande na mesma medida dos desnivelamentos sociais. Se a técnica possibilita a criação e a potencialização de discursos, faz circular imaginários a serem interpretados. Tais discursos evitam a obscuridade, onde seria possível encontrar diferentes graus da realidade, apreendidos de um mundo que tem algo-a-dizer para alguém.

Neste sentido vale contrastar a banalidade do excesso de palavras na mídia, onde reina a polifonia e o tautismo ${ }^{10}$ com a origem da palavra no pensamento em Heráclito. ${ }^{11}$

Ao longo do tempo, a moral foi um sedativo para os instintos que poderiam ter despertado outros valores. Mesmo em pleno niilismo, a moralidade sobrevive $\mathrm{e}$ hipnotiza a vontade criadora do homem moderno:

"Hoje o gosto e a virtude do tempo enfraquecem e diluem a vontade, nada é tão atual como a fraqueza de vontade: em conseqüência, no ideal do filósofo devem ser incluídas na noção de 'grandeza' justamente a força da vontade, a dureza e a capacidade para decisões largas; com a mesma justificativa com que a doutrina inversa e o ideal de uma humanidade."12

No mesmo aforismo, Nietzsche afirma ser necessário estar contra o tempo e seus homens, como uma forma de estranhamento que $o$ andarilho necessita para criar, destruir e recriar.

As palavras carregam vontade de poder. O homem descobriu que a moral como "dever ser" era eficaz para equilibrar comportamentos. Qualquer desvio dos instintos que levam à vontade é melhor que a perda do controle. Transmitir a moral através das palavras. Criar um código de palavras e pregar conceitos idealistas. Nada mais próximo de um platonismo do que escrever conceitos com imagens e iluminar as cenas para a contemplação do mundo técnico, onde o homem se busca como destino. Se as palavras escaparam da ação afirmativa do pensador e se tornaram alheias à vontade individual, o sentido só é possível na troca. Dar nome às coisas, diferenciar os graus de acertos e erros e interpretar eram atributos do pensamento tanto de Heráclito como de Nietzsche.

Assim, o pensador alemão relaciona o homem, a verdade e as palavras em uma crescente influência da instituição que industrializa a idéia, sob a forma de um acesso à verdade da sociedade européia. Cada vez mais politizada, democrática e capitalista, assim como centro de vontades de rebanho. Surge aos olhos de Nietzsche uma crítica possível, e ainda prematura, de uma teoria utilitarista e desonesta da comunicação, onde a imprensa é fundamental para o Estado.

O pensador destaca como interesses econômicos atuam sobre a opinião pública e o jornalista e geram uma moral que coloca a imprensa como o espaço onde se digladiam silenciosamente egoísmo e altruísmo. O valor moral do jornalismo transmite a crença na verdade como se fosse uma verdade em si. ${ }^{13}$

A Alemanha vista por Nietzsche era nacionalista e capitalista. A cultura se encontrara em uma característica típica do que ele chamava de "filisteus". Assim como a palavra perdeu sua essência quando aprisionada pelos sábios, os primeiros "tiranos do espírito", ${ }^{14}$ ela encontra na aurora da mídia de massa o cenário propício para sua expansão em termos de "expressão lingüística" relativizada e reduzida pela linguagem dos media.

Se a cultura e a linguagem obedecem a uma lógica moral, os entusiastas da época têm, no final do século passado, as ressacas da metafísica e da religião como legitimadoras da ciência e do progresso. Para tal, Ihes faltaria um acerto de contas cultural com o demasiado humano, 
Nietzsche. ${ }^{15}$

O fluxo potencial da cultura ao "solidificar-se" perde o sentido da vida e passa a ser mais uma máscara da vontade de rebanho, essencial para a moral dos ideais ascéticos. Porém, o cenário moderno é uma via para o niilismo. Uma vez superado o terror do transcedental, há o descentramento dos valores seculares e os movimentos cristalizam-se na sombra dos ídolos ou das verdade inquestionáveis.

Desta forma parece estar a técnica moderna, como horizonte e como parte irreversível do devir. Heidegger acredita que: "O fundamento e o âmbito essencial da técnica moderna é essa vontade, que em toda intenção e apreensão, em tudo o que se quer e alcança, sempre quer somente a si mesma (...) A técnica é a organização e o órgão da vontade de vontade. Os grupos humanos, os povos e as nações, os grupos e os indivíduos não passam, em toda parte, de queridos dessa vontade e não sua origem e seus senhores, mas são quase tão-somente cumpridores de má vontade."16

No fundo da questão, a origem obscura do pensamento ocidental: a autonomia de espíritos livres capturada pelas redes da vontade de elevar-se. Uma estrutura metafísica explicada pelos sábios e onde o homem não tem um "fora" como opção. Na técnica moderna, o discurso é o da vontade de utilitarismo e hedonismo, ainda que as pessoas não sintam qualquer cerceamento, uma vez que, ao não perceberem que estão "dentro", o "fora" ou um devir outro perdem o sentido. As vontades são reconhecidas e satisfeitas, estimuladas e embriagadas, não por Dioniso, mas pela ordenação das múltiplas vontades humanas pela própria técnica. ${ }^{17}$

Para o jogo heraclitano também fazem falta a vontade e a inocência. Ao se considerar o mundo como casualidade e erro, o pensamento ganha novas dimensões. As algemas milenares da metafísica, religião e moral, são transfiguradas e atualizadas de acordo com as culturas. No centro da civilização ocidental contemporânea se abre uma fenda obscura, não pela dificuldade de se fazer entender, mas porque ela remonta as origens do pensamento. Em uma época de deuses mitológicos, sem qualquer tipo de terrorismo ou sentimento de vingança nas sabedorias.

O caráter obscuro do início da aventura humana em termos de pensar é sintoma se uma profundidade interior e não da inconsistência do pensador, do pensamento ou do a-se-pensar. As palavras e as coisas ligadas pela lógica. Uma visão anterior à distinção entre ser e ente. Quando Nietzsche pretendia retornar aos pré-socráticos, era o pensamento da origem que o acompanhava: o tempo que antecedeu ao desvio do pensamento para a metafísica. Como propor uma tresvaloração de todos os valores sem vislumbrar na história o momento de triunfo dos rivais dos filósofos do futuro.

Aconteceu em Platão, quando o mundo verdadeiro derrotou o mundo aparente a partir da elevação do bem pela idéia. ${ }^{18} \mathrm{O}$ mundo do sábio é o único que tem valor. Ele usou palavras para separar o homem de seu mundo e, portanto, tirou-o de sua potência vital. No mundo aparente ou sensível restaram os conduzidos como rebanho.

Nietzsche admirava a nobreza por sua força e vitalidade. Em contrapartida, quando a potência tende ao conformismo surge uma ausência de vontade para interpretar. Todos os valores seguem a orientação da vontade. Se não for possível que o homem possa, a vontade será a de outro: homem ou instituições da civilização moderna ou pós-moderna.

Entre tantas possibilidades de devir, e ele acabou esfacelado em sua multiplicidade original, dando lugar a uma multiplicidade liberada de tradicionais valores, mas programado a partir do devir do mundo com a técnica. A técnica não possui devir, mas ela está no horizonte de qualquer devir afirmado em um mundo 
que já não é capaz de inocência nem de assumir seu passado.

Parece tarde para voltar ao início e criar valores e pensamentos humanos sem que a positividade e o entusiasmo do homem perante a técnica pareça deixar passo para um novo humanismo, onde o homem seja a potência de sua existência ou um "fragmento de destino" como pondera Nietzsche. ${ }^{19}$

O obscuro da origem contrasta com a luz de Artemis. Heráclito pensava a deusa e o devir. Homem e natureza acabam separando-se duas vezes: a primeira vez, quando o ser tornou-se o a-se-pensar; e a segunda, quando a lógica passou para a técnica.

O pensamento deve ao mundo uma antiga revelação: "Os modos de vida inspiram maneiras de pensar, os modos de pensar criam maneiras de viver. A vida activa o pensamento e o pensamento, por seu lado, afirma a vida (...)Este segredo dos pré-socráticos de uma certa maneira já estava perdido desde a origem. Devemos pensar a filosofia como uma força." ${ }^{20}$

No devir do mundo restam possibilidades para a afirmação do pensamento como potência vital. Se a força não enfraquecer, será a vez da vontade de buscar o a-se-pensar no mundo, novamente. O pensamento crescerá solitário, se refugiará nas montanhas, como na década de filósofo errante de Nietzsche, e voltará para afrontar qualquer tempo futuro, inclusive o atual, que o reduz ao consenso sedutor da moral da positividade tecnológica .

\section{Notas}

1 Nietzsche já tratou de analisar suas próprias intenções em Ecce Homo (EH). 0 presente texto está basedo nas obras traduzidas ao português por Paulo César de Souza (São Paulo, Companhia das Letras) e Maria Inês Maria de Andrade (A filosofia na idade trágica dos gregos, Lisboa, Edições 70). Ao francês por Cornélius Heim (edição elaborada por Giorgio Colli e Mazzino Montinari.
Paris, Éditions

Gallimard, 1971) e ao espanhol, por Francisco Javier Carretera Moreno e Luíz Díaz Marín. (Madrid, M.E. Editores, 1994).

\section{Crepúsculo dos ídolos (Cl), II $§ 5$.}

3 Conceito é um fio condutor que atravessa a obra de Nietzsche a partir de Humano, Demasiado Humano (H). Apesar de estar disperso em diversos aforismos, ele encontra na Genealogia da Moral (GM) uma obra dedicada a sua análise. Sugere-se o prólogo e os dois primeiros tratados.

$4 \mathrm{GM}, \mathrm{I}, \S 10$.

$5 \mathrm{GM}, \| l, \S 8, \S 9$ e 10.

6 Neste sentido, Nietzsche escreve sobre Heráclito: A Filosofia na Idade Trágica dos Gregos, VII: "Neste mundo só o jogo do artista e da criança tem um vir à existência e um perecer, um construir e um destruir sem qualquer imputação moral em inocência eternamente igual."

$7 \mathrm{Cl}, \mathrm{Il}, \S 10 \mathrm{e} \S 11$.

8 Heidegger escreve sobre a relação de Heráclito com a deusa Artemis como um a-se-pensar e as palavras como um a-se-dizer. Sobre a estória do jogo de dados com crianças no templo de Artemis: "Nos próximos passos deveremos prestar atenção se, e em que sentido, 0 pensamento de Heráclito sempre se determina pela proximidade do jogo, e se algo como jogo chega a revelarse no pensamento pensante do a-se-pensar". Heidegger, M. Heráclito. Rio de Janeiro: Relume Dumará, 1998. P.28.

9 Foucault, M. Nietzsche, Freud \& Marx. São Paulo: Princípio, 1997. pp. 23-24.

10 Expressão criada por Lucien Sfez como tipo híbrido de tautologia e autismo, que pode ser remetida à ciência e também aos discursos da mídia. Sfez, L. Critica da Comunicação. São Paulo: Loyola, 1996.

11 "Se medirmos a nobreza da palavra pelo que ela tem a dizer, o que então haveria de mais adequado do que um fragmento de Heráclito?(...) 0 que funda, porém, a nobreza originária desta linguagem pensante não é um talento especial para a linguagem que possui este pensador, mas a própria essência do que se pensa e do que nesse pensamento constitui-se 0 a-se-pensar (...) Na origem da 
saga, a palavra ainda não decaiu, transformando-se em mera 'expressão lingüística' ou alienando-se em 'locuções' que podem facilmente ser substituídas umas pelas outras. Aqui a palavra ainda se acha em sua essência originária - a palavra -, sem que os poetas e pensadores originários tenham domínio ou precisem dominar um saber sobre a essência velada da palavra.

Enquanto fundamento da palavra nobre, o que no pensamento originário constituiu-se 0 a-se-pensar é certamente, também, o fundamento da obscuridade desse pensamento. Heidegger.M. op.cit. p.43.

12 Além do Bem e do Mal (ABM) § 212.

13 "Utilização da pequena desonestidade. - 0 poder da imprensa consiste em que todo indivíduo que para ela trabalha sente-se muito pouco comprometido e vinculado. Em geral ele diz sua opinião, mas ocasionalmente não a diz, para ser útil a seu partido, à política de seu país ou a si mesmo. Esses pequenos delitos da desonestidade, ou apenas da reticência desonesta, não são difíceis de suportar para o indivíduo, mas suas conseqüências são extraordinárias, porque tais delitos são cometidos por muitos ao mesmo tempo. Cada um deles diz para si: 'Com serviços tão diminutos vivo melhor, posso ganhar a vida; se recuso essas pequenas considerações, eu me torno impossível'. Como moralmente parece não importar escrever ou deixar de escrever uma linha a mais - talvez sem assinar, além disso -, alguém que possua dinheiro e influência pode transformar qualquer opinião em opinião pública. Quem sabe que a maioria das pessoas é fraca nas pequenas coisas e, deseja alcançar seus objetivos através dela, é sempre um indivíduo perigoso." ABM, § 447.

14 Cf. $H, \S 261$.

15 "Fundição da cultura - A cultura se originou como um sino no interior de uma camisa de material grosseiro e vulgar: falsidade, violência, expansão ilimitada de todos os Eus singulares, de todos os diferentes povos, formavam essa camisa. Será o momento de retirá-la? Solidificou-se 0 que era líquido, os impulsos bons e úteis, os hábitos do coração nobre tornaram-se tão seguros e universais que já não é preciso apoiar-se na metafísica e nos erros das religiões, já não se requer dureza e violência, como 0 mais poderoso laço entre homem e homem, povo e povo? - Para responder essa questão não temos mais um Deus que nos ajuda: é nossa inteligência que deve decidir. Em suma, o próprio homem deve tomar nas mãos o governo terreno da humanidade, sua 'onisciência' tem que velar com olhos atentos 0 destino da cultura." $\mathrm{H}, \S 245$.

16 Heidegger, op.cit. p.205.

17 Sobre Nietzsche e a técnica, recomenda-se no Andarilho e sua sombra, apêncice de Humano, demasiado humano: "rechazo de la cultura de la maquina - La maquina, producto de la capacidad intelectual más elevada, no moviliza en las personas que la manejan, más que sus fuerzas interiores e irrefleivas. Bien es cierto que su acción desencadena una suma se fuerzas enorme que, en caso contrario, hubieran permanecido dormidas; pero no fomenta las ganas de educar-se, de hacer las cosas mejores y com más arte. Nos hace activos y uniformes, lo que produce a la larga un efecto contrario: un aburrimiento extremo se apodera del alma que aspira, por medio de la máquina, a un ocio muy dinámico." Nietzsche, El caminante y su sombra. Madrid. ME Editores, 1994, § 220.

18 Ver em Cl, A 'razão' na filosofia e sobre como o mundo verdadeiro acabou se convertendo numa fábula.

19 "Zaratustra o primeiro psicólogo dos bons, é - em conseqüência - um amigo dos maus. Se uma espécie decadente de homem ascendeu à posição de espécie suprema, isso pode acontecer somente à custa da espécie contrária, a espécie forte e segura da vida. Se 0 animal de rebanho resplende no brilho da virtude mais pura, o homem-exceção tem de ser rebaixado a homem mau. Se a mendicidade reivindica a todo preço a palavra verdade para a sua ótica, o verdadeiramente veraz deverá ser encontrado sob os piores nomes. Zaratustra não deixa nisso dúvidas: diz haver sido precisamente 0 conhecimento dos bons, dos 'melhores' que the inspirou o horror ao homem; dessa repulsa the teriam crescido as asas para 'voejar para futuros longínquos' - ele não esconde que seu tipo de homem, um tipo relativamente sobre-humano, é sobre-humano precisamente em relação aos bons, e que os bons e justos chamariam de demônio seu além-do-homem" (A tradução de Scarlett Marton, que difere do super-homem, na tradução de Paulo César de Souza, é mais fiel à idéia do autor). EH, por que sou um destino, $\S 5$.

20 Cf. Deleuze, G. Nietzsche, Lisboa, Edições 70. pp. 17-18. 